\title{
Socio-demographic and nutritional determinants of birth weight.
}

\author{
Shafiqul Islam Khan ${ }^{*}$, Diruba Easmin Jhorna², Atul Chakma², Abu Tareq ${ }^{1}$, Musammet Rasheda \\ Begum $^{3}$ \\ ${ }^{1}$ Department of Food Microbiology, Faculty of Nutrition and Food Science, Patuakhali Science and Technology \\ University, Dumki, Patuakhali. Bangladesh. \\ ${ }^{2}$ Department of Human Nutrition and Dietatics, Faculty of Nutrition and Food Science, Patuakhali Science and \\ Technology University, Dumki, Patuakhali. Bangladesh \\ ${ }^{3}$ Department of Agricultural Economics and Social Sciences, Chittagong Veterinary and Animal Sciences University, \\ Khulshi, Chittagong, Bangladesh
}

\begin{abstract}
Global high prevalence of low birth weight (LBW) is a major public health concern leads to high neonatal and infant deaths. This study was conducted to find out the prevalence of low birth weight and to effect of associated socio-demographic and nutritional predictors. A total of 200 respondents were approached from January 2016 to June 2016. Data were collected on sociodemographic and nutritional factors by interviewing pregnant mothers. Hemoglobin level and blood pressure data were recorded from mothers' antenatal care card. Descriptive data revealed that the prevalence of low birth weight was $17 \%$. Correlation matrix showed age and hemoglobin concentration significantly associated with birth outcome. Regression analysis portrayed that one unit increased age and hemoglobin corresponds to the respectively 0.017 and 0.050 unit increased birth weight of the child. To be concluding, teenage mothers and low hemoglobin level were the important risk factors for low birth weight in the study area.
\end{abstract}

Keywords: Low birth weight, Factors, Nutritional determinants

Accepted on February 21, 2018

\section{Introduction}

Low birth weight (LBW) is a major determinant of morbidity, mortality and disability in infancy and childhood [1]. It is associated with the age of the mothers [2,3] marital age and parity [4-7] maternal education [8] family income, poverty and employment status Hemoglobin $(\mathrm{Hb})$ and blood pressure (BP) also affected the LBW [3,9]. Maternal hypertension increased intrauterine growth restriction and LBW [3,10,11]. Prevalence of LBW is quite high in developing countries. In Bangladesh, there is a high prevalence of low birth weight babies and high morbidity and mortality among the under five children [12]. No research data are available for the study areas. Rates and associated factors might be varying here for quite different socio-demographic and ethnic composition of mother. More over researchers have shown inconsistent results in other areas of Bangladesh. The study was conducted to find out the prevalence of LBW and associated factors in the study area.

\section{Materials and Methods}

\section{Study design}

A hospital based descriptive cross-sectional study design was used in conducting this study. The study hypothesized that sociodemographic and nutritional factors affect the birth outcome.

\section{Study area}

This study was conducted in Sadar area Rangamati district. The Rangamati district is located in the south-eastern area of Bangladesh. It is the largest district of the country about 350 kilometers from capital Dhaka.

\section{Study population}

The total population in this study was 200 . The study population comprised of pregnant mothers. The women were approached from Rangamati Matrimongol center, a non-government maternal care center.

\section{Questionnaire design}

The study instruments constitute a questionnaire emphasizing on socio-demographic data like name, address, age, occupation, husband's occupation, education and maternal nutritional others data such as hemoglobin status, anemia, parity, gravitas, blood group, blood pressure, oedema, urine sugar, HbsAG and child data (date of delivery, gestational age, sex, birth weight). This study was conducted through an in-depth interview by administration of questionnaires.

\section{Data collection}

Relevant information for the hospital based survey was gathered using a structured questionnaire. All the participants were interviewed at an arranged time, through a questionnaire that asked for maternal predictors. Another source of information that was used from the pregnant woman's ANC card, which served as backing for gathering information such as blood pressure measurements, hemoglobin status, gestational age, number of parity and blood parameters. The value lower than $11 \mathrm{~g} / \mathrm{dL}$ was considered anemia as recommended by the World Health Organization for a pregnant woman [13].

\section{Statistical analysis}

Means and standard deviations (SD) were calculated for all 
maternal anthropometric parameters, gestational age, and birth weight. The degree of correlation was measured between birth weight and maternal characteristics including hemoglobin status. Linear and logistic regression models were used to analyze data. Linear regression model was applied to observe the relationship between birth weight of child and maternal characteristics. Binary Logistic Regression model was used to estimate the probability of a binary response (birth weight, $<2500$ gm=under normal and $\geq 2500$ gm=normal) based on maternal characteristics, it allows say that the presence of a risk factor increases the probability of a given outcome by a specific percentage. Statistical analysis was performed using the software SPSS 16.0 and SAS 9.3 considering significance level $5 \%$.

\section{Results}

\section{Descriptive statistics of maternal characteristics}

Maternal characteristics where almost $40 \%$ mother belongs to less than 20 years group. High educated mother was 3.5\% and $38.5 \%$ suffering from illiteracy. About 49 percentage mothers were married at teenage, on the contrary, there was no saying percentage above thirty years. The primipara mother's percentage was $58.5 \%$ whereas the third gravida mothers were only $2.5 \%$. Most of the gestational age was $\leq 37$ weeks. Buddhist mothers comprise the $98 \%$ of the study population and, $86.5 \%$ mother was unemployed. On the other hand, $33.5 \%$ husband was unemployed. B+ blood group mother was $41 \%$ and the next $25 \%$ blood group was $\mathrm{O}+$, clinically anemic mother was $75 \%$, and nulliparous mother was $54 \%$ in this study. All participants were free from sugar, HbsAg and VDRL and the low birth outcome was $17 \%$ (Table 1 ).

\section{Averages of maternal characteristics and birth weight}

Maternal characteristics and birth weight, It showed that mother age range between 18 and 38, where maximum mother age was 25 , and most of them were married in age 20 years. The systolic and diastolic blood pressure range was 90 to 170 and 60 to 120 . The average hemoglobin level was $10.57 \mathrm{mg} / \mathrm{dl}$. Most of the gestational age was 37 weeks. The minimum and maximum birth weight of child was $1.8 \mathrm{~kg}$ and $4.4 \mathrm{~kg}$ (Table 2).

\section{Correlation of predictors with birth weight}

The correlation between maternal characteristics and birth weight with p-value. It portrayed that all the parameters were insignificant except age of mother $(\mathrm{P}$ value $=0.041)$ and hemoglobin $(\mathrm{P}$ value $=0.038)$. There is a positive correlation between birth weight and age of mother. The means birth weight increases with age. There is positive relationship among gestational age, parity and birth weight. It also bears a negative relation between blood pressure and birth weight. That means one more reduction one will increase (Table 3).

\section{Effects of determinants on birth weight}

The linear regression model was performed with backward selection method significance level staying 0.10 for all maternal characteristics and birth weight. The final model contains only two parameters and fits the model $(\mathrm{F}=1.39$, $\mathrm{p}$-value=0.11). It was observed from the Table 4 describes Parameter estimate of linear regression model that age and hemoglobin were positively related to birth weight. One unit increases in the age of mother and hemoglobin level corresponds to the 0.017 and 0.050 unit increased birth weight of the child. None of the other parameters were found significant in logistic regression model.

\section{Discussion}

In this study, the prevalence of LBW was $17 \%$. This result is almost consistent with [14] in Nigeria where it was $14 \%$ in their study. But the survey of South Asian countries (2003-2004) showed that the prevalence was $36 \%$ in Bangladesh, 30\% in India, $21 \%$ in Nepal, $15 \%$ in Bhutan and, $22 \%$ in Maldives. That differences with Bangladesh data may be due to this was a hospital based study and conducted in a different ethnic society where $98 \%$ was chakma mothers. Mean birth weight

Table 1. Descriptive statistics of maternal characteristics.

\begin{tabular}{|c|c|c|}
\hline Characteristics & Frequency $(\mathrm{N}=200)$ & Percentage (\%) \\
\hline \multicolumn{3}{|c|}{ Age } \\
\hline$<20$ yrs & 80 & 40 \\
\hline $20-30 y r s$ & 109 & 54.5 \\
\hline$>30 \mathrm{yrs}$ & 11 & 5.5 \\
\hline \multicolumn{3}{|c|}{ Religion } \\
\hline Buddist & 196 & 98 \\
\hline Hindu & 4 & 2 \\
\hline \multicolumn{3}{|c|}{ Education } \\
\hline Illiteracy & 77 & 38.5 \\
\hline Primary education & 72 & 36 \\
\hline High school & 44 & 22 \\
\hline Graduate and above & 7 & 3.5 \\
\hline \multicolumn{3}{|c|}{ Profession of mother } \\
\hline Employed & 173 & 86.5 \\
\hline Unemployed & 27 & 13.5 \\
\hline \multicolumn{3}{|c|}{ Age at marriage } \\
\hline$<20$ yrs & 99 & 49 \\
\hline $20-30 y r s$ & 100 & 50 \\
\hline$>30$ yrs & 1 & 0.5 \\
\hline \multicolumn{3}{|c|}{ Gravida } \\
\hline $\mathrm{G}_{1}$ & 117 & 58.5 \\
\hline $\mathrm{G}_{2}$ & 78 & 39 \\
\hline$\geq \mathrm{G}_{3}$ & 5 & 2.5 \\
\hline \multicolumn{3}{|c|}{ Gestational age of the newborn } \\
\hline$\leq 37$ wks & 19 & 9.5 \\
\hline $38-40$ wks & 151 & 75.5 \\
\hline$>40$ wks & 8 & 4 \\
\hline \multicolumn{3}{|c|}{ Birth weight } \\
\hline$<2.5 \mathrm{~kg}$ & 34 & 17 \\
\hline $2.5-3.5 \mathrm{~kg}$ & 136 & 68 \\
\hline$>3.5 \mathrm{~kg}$ & 20 & 10 \\
\hline \multicolumn{3}{|c|}{ Hb Concentration, g/dl } \\
\hline$\leq 10.9$ & 117 & 58.5 \\
\hline$\geq 11$ & 50 & 25 \\
\hline
\end{tabular}

Table 2. Averages of maternal characteristics and birth weight.

\begin{tabular}{|c|c|c|c|c|c|}
\hline Variables & Mean & Std Dev & Mode & Minimum & Maximum \\
\hline Age of mother & 25.12 & 4.54 & 25 & 18 & 38 \\
\hline Age of marriage & 20.08 & 3.71 & 20 & 11 & 33 \\
\hline Blood pressure (sys) & 121.98 & 17.31 & 120 & 90 & 190 \\
\hline Blood pressure (dias) & 80.31 & 11.84 & 80 & 60 & 120 \\
\hline Hemoglobin mg/dl & 10.57 & 1.16 & 10.8 & 6.6 & 15.7 \\
\hline Gestational age (WKS) & 36.77 & 1.89 & 37 & 27 & 42 \\
\hline Weight of child (kg) & 3 & 0.45 & 3000 & 1.8 & 4.4 \\
\hline
\end{tabular}


Table 3. Pearson correlation between maternal characteristics and birth weight.

\begin{tabular}{|c|c|c|c|c|c|c|}
\hline Variables & $\begin{array}{c}\text { Child } \\
\text { Weight }\end{array}$ & Age of mother & Age of marriage & $\begin{array}{c}\text { BP } \\
\text { systolic }\end{array}$ & BP diastolic & Hb level \\
\hline Weight of child & 1 & & & \\
\hline Age of mother & $0.147^{\star \star}$ & 1 & & \\
\hline Age of merry & 0.069 & 0.516 & -0.049 & 1 & \\
\hline BP systolic & -0.048 & 0.059 & -0.058 & 0.792 & 1 \\
\hline BP diastolic & -0.097 & -0.005 & 0.047 & 0.150 & 0.130 \\
\hline Hemoglobin & $0.115^{\star *}$ & 0.076 & 0.062 & -0.177 & -1 \\
\hline Gestational age & 0.020 & 0.019 & & \\
\hline
\end{tabular}

Table 4. Parameter estimate of linear regression model.

\begin{tabular}{|c|c|c|c|c|}
\hline Parameters & Estimate & St. Error & t Value & P-value \\
\hline Intercept & 3.111 & 0.359 & 8.66 & $<.0001$ \\
\hline Age of mother & 0.017 & 0.008 & 2.17 & 0.0313 \\
\hline Hemoglobin & 0.050 & 0.030 & 1.65 & 0.0411 \\
\hline
\end{tabular}

was found 3000 gms. In the study which was very similar 2961 gm by reported by Deshmukh JS et al. [15] in Bangladesh and a bit lower 2669 gms by Manyeh AK et al. [16] in India. In this study, there was a significant association between the age of the mothers and low birth weight. Similar types of results were found by Bugssa G [17] in Ghana and by Johnson D [18] in Northern Ethiopia. But opposite information described for Georgia, where low birth was insignificantly associated maternal age. Findings of the relation of LBW with gestational age and educational level were not found to be statistically significant. But significant associated found by Ahankari A et al. [19]. Also correlate with the observation in Pakistan [20]. But significant association observed by John G [21]. Although, no association noticed by the study done by [22]. An inverse relationship between birth weight and blood pressure was also found in this study, which was supported by the studies of other researchers $[23,24]$. Even though, significant relationship reported [25].

\section{Conclusion}

This study suggests that there is several factors interplay which leads to low birth weight babies in the study area. Socio demographic factors like maternal age, educational level, economic status, nutritional status, and anemia are very important. The results of this study suggest that for reducing low birth weight, the strategy needs to focus attention on nutrition education to facilitate better weight gain during pregnancy encouraging wider birth interval and discouraging teenage pregnancy.

\section{Acknowledgments}

The authors expressed deep gratitude to Rangamati Matrimongol center, a maternal health care center, for make unrestricted opportunity and logistic support to collect the necessary data. The contributions of all doctors and technicians and field health workers of the clinic related to this work are gratefully acknowledged. Finally, the authors would like to thank all participating mothers who took part in this study.

\section{Ethical Approval}

The study was approved by the Medical Ethical Committee of the Rangamati Matrimongol center, headed by the director of clinic. All procedures performed in studies were in accordance with the ethical standards of the institutional research committee and with the 1964 Helsinki declaration and its later amendments or comparable ethical standards.

\section{Informed Consent}

Informed consent was obtained from all individual participants included in the study. Author disclosure. All authors contributed substantially to, the design and drafting of work, critical review, and approved the final version of the manuscript for submission.

\section{Conflict of Interest}

All authors declare that they have no conflicts of interest.

\section{Reference}

1. Kader M, Perera NKP. Socio-Economic and nutritional determinants of low birth weight in India. N Am J Med Sci. 2014;6:302-8.

2. Gibbs CM, Wendt AA, Peters SS, et al. The impact of early age at first childbirth on maternal and infant health. Paediatr Perinat Epidemiol. 2012;26:259-84.

3. Yadav S, Choudhary D, Narayan KC, et al. Adverse reproductive outcomes associated with teenage pregnancy. Mcgill J Med. 2008;11:141-4.

4. MacLeod S, Kiely JL. The effects of maternal age and parity on birth weight: a population-based study in New York City. Int J Gynaecol Obstet. 1988;26:11-9.

5. Feleke Y, Enquoselassie F. Maternal age, parity and gestational age on the size of the newborn in Addis Ababa. East Afr Med J. 1999;76:468-71.

6. Vega J, Sáez G, Smith M, et al . Risk factors for low birth weight and intrauterine growth retardation in Santiago. Chile. Rev Med Chil. 1993;121:1210-9.

7. Torres-Arreola LP, Constantino-Casas P, Hernández SF, et al. Socioeconomic factors and low birth weight in Mexico. BMC Pub Hlth. 2005;5:20

8. Murphy JF, O'Riordan J, Newcombe RG, et al. Relation of hemoglobin levels in first and second trimesters to outcome of pregnancy. Lancet. 1986;3:992-56.

9. Preterm delivery, low birth weight, neonatal risk in pregnant women with high blood pressure. BMJ British Med J. 2014.

10. Xiong X, Mayer D, Demianczyk N, et al. Impact of pregnancy-induced hypertension on fetal growth. Am J Obstetr Gyneco. 1999;180:207-13. 
11. Hossain S, Azhar BS, Islam SK, et al. Maternal sociodemographic factors and anthropometric characteristics related to infant birth weight. J Pharm Biomed Sci. 2013;29:788-97.

12. Isiugo-Abanihe UC, Oke OA. Maternal and environmental factors influencing infant birth weight in Ibadan, Nigeria. Ibadan. Afr Pop Stud. 2011;25:1-17.

13. World Health Organization. Feto-maternal nutrition and low birth weight. 2010 .

14. Hosain G, Chatterjee N, Afroza B, et al. Factors associated with low birth weight in rural Bangladesh. J Tropic Pediatr. 2006;52:87-91.

15. Deshmukh JS, Motghare DD, Zodpey, et al. SP Low birth weight and associated maternal factors in an urban area. Ind Paediatr. 1998;35:33-6.

16. Manyeh AK, Kukula V, Odonkor G, et al. Socioeconomic and demographic determinants of birth weight in southern rural Ghana: evidence from Dodowa Health and Demographic Surveillance System. BMC Pregnancy Childbirth. 2016;16:160.

17. Bugssa G, Dimtsu B, Alemayehu M. Socio demographic and maternal determinants of low birth weight at Mekelle Hospital, Northern Ethiopia: A cross sectional study. Amer J Adv Drug Delv. 2014;2:609-18.
18. Johnson D. The Association between maternal age and low birth weight offspring, NHANES 2007-2008. Pub Hlth. Iph theses 329. 2014

19. Ahankari A, Bapat S, Myles P, et al. Factors associated with preterm delivery and low birth weight: a study from rural Maharashtra, India. F1000 Res. 2017:6-72.

20. Shami SA, Khan A. Maternal age and parity effects on human birth weight: a hospital survey from Lahore (Punjab), Pakistan. J Pak Med Assoc.1980;30:131-7.

21. John G. Mechanism for the association of maternal age, parity and birth spacing with infant health. Health issues for women and children. National Academy Press. 1991:96-139.

22. Andayasari L, Opitasari C. Parity and risk of low birth weight infant in full term pregnancy. Hlth Sci J Indo. 2016;7:13-16.

23. Singhal A, Cole TJ, Fewtrell MS, et al. Is slower early growth beneficial for long-term cardiovascular health? Circulation. 2004;109:1108-13.

24. Troy LM, Michels KB, Hunter DJ, et al. Self-reported birth weight and history of having been breastfed among younger women: an assessment of validity. Int J Epidemiol. 1996;25:122-227.

25. Steer PJ, Little MP, Kold-Jensen T, et al. Maternal blood pressure in pregnancy, birth weight, and perinatal mortality in first births: prospective study. BMJ. 2004;4:329-1312.

\section{*Correspondence to:}

Md Shafiqul Islam Khan

Department of Food Microbiology

Patuakhali Science and Technology University

Dumki

Patuakhali

Bangladesh

Tel: +8801712115973

E-mail: msikhan312@yahoo.com 